\title{
Africa's Amazing Story in the World of Education
}

\section{Professor Tuntufye Selemani Mwamwenda}

Nelson Mandela Metropolitan University

Doi:10.5901/mjss.2014.v5n20p1668

\begin{abstract}
In view of the importance of Education in the development of Africa, the present investigation aimed at looking at Education at Primary, Secondary, Tertiary and University, as it has existed for the past thirty years. Fifteen African countries selected from five major geographical regions of Africa; linguistically represented by French, English and Arabic participated in the study. The results showed that every system of education level, great achievements have been made. The number of children attending primary school has reached the level of universal primary education in most of the countries. There are more universities there ever have been.
\end{abstract}

Keywords: Africa and Education, university education, universal primary education, education for all, self-reliance in workforce, all Africa research.

\section{Introduction}

African countries realize and embrace the fundamental importance of education, for without education, there can be no meaningful development (African Union, 2008) Through education, there is interrelated and interdependent sets of human capacity that predispose a person to think, to know and to act in the context of social awareness, as well as values and skills. In fact, education is the corner stone for sustainable development; it is a tool for producing and managing human resources; for inculcating values, thus ensuring the common bond of humanity in a global village; a tool for scientific research and technology (African Union, 2008).

\section{Literature Review}

Mwencha (2010), deputy chairperson of the African Union Commission asserts that "Africa has for some time now, decided 0 anchor its development of education" . For a country or a continent, there is no greater wealth than well-trained human resources. Kadar Asmal, former Minister of Education in South African, addressing

African Ministers of Education, argued that education is not only critical, but also a solid foundation for both the reconstruction and Moreover, Education does not only contribute to economic development, but also contributes to a sustainable democratic society, as its graduates positively contribute in the governance of their society

Addressing African Union Ministers of Education in Johannesburg, former Deputy President of South Africa, Phumzile Mlambo-Ngcuka (2007), preambled her speech as follows: "As Ministers of Education of the 53 member- states of the African Union, your task, destiny and even privilege is to do your bit even against all the odds to take an African child from the worst possible background, invest in them through education and change their reality for ever" She went on to point out that the reason the African Union is committed to education is that it transforms lives and contributes to success and prosperity in society.

Education is liberating both for a given individual and society at large. This is re-echoed in the African Ministers of Education collective conclusion that they are convinced beyond doubt, that Education is the key to combat poverty and create spur opportunity for the young people of Africa, for as they master reading, writing and numeracy their potential for success in life is beyond estimate.(Fast Track Initiative, 2009)

In view of this, the present study has its objective as a review of three decades of education development for Africa, as agreed upon by Ministers of Education in the African Union. In this context, a brief account will be given on the three decades of education development for Africa in terms of its objectives and goals, and the extent to which such goals have been achieved in various African countries. 


\section{Method}

\subsection{Sample and Population}

Africa is a huge continent consisting of 54 countries and a population of over $t$ a billion people. This poses a gigantic task for the proposed study. This poses further complication, when one takes into account the numerous cultures and languages existing and being used in these countries.

The questions raised were should every African country participate in the study? If so, was it feasible to communicate with each one in their own official languages? Similarly, are 54 countries not too many to constitute a sample for the study? Would a random sample of about ten or 15 countries be good enough to serve the purpose? In the random sample, would all countries be involved irrespective of their official languages?

The sample participating in this study was based on the five regions of the African Union, namely North Africa, Southern Africa, Central Africa, East Africa and West Africa. From each of these five regions, four countries, making a total of twenty countries were selected based on the size of the country's population. Such selection comprised small and large countries. Equally important, each of the four major official languages: English, French, Portuguese and Arabic were represented. Spanish was not included, given the small number of people using it in Africa. Figure 01 is a map of Africa displaying the participating countries. There is a reduction in the number of participating countries from 20 to 15 , due to logistic problems, and therefore were dropped from the original list.

\subsection{Instrument}

Interviews based on a questionnaire were conducted with senior officials in the Departments of Education for each one of the 15 participating countries. Another source of information in terms of statistical data was solicited from the Departments of Education. Other statistical information was retrieved from the literature review.

\subsection{Procedure}

Research assistants were selected from each countries university to carry out the interviews with officials in the Department of Education and collect the data from other sources from the identified sources.

\section{Results}

The results of the interviews and other sources of information are reported here for each one of the 15 participating countries. Specifically the results are informed by answers provided in the questionnaire and the various documents provided by the Departments of Education and others sources where similar data and information was secured. Results .

\subsection{Primary School Education}

In an individual educational profile, not much attention is devoted to one's primary education, as it is to the University attended and degree conferred. Yet no one would have attended university, and conferred a degree without the foundation of primary education. This only goes to confirm.

$\mathrm{s}$ has continued unabated, as the then government and the present government continued putting up more schools. For example, in 1978 there were 78 schools which rose to 647 by 1991 . Correspondingly, the enrolment rose from 145,457 to 278,812, respectively (Botswana Government, 1993).

Teaching and learning materials were provided, as well as professional teachers graduating from Colleges of Education and the University of Botswana. Such provision has had impact on the education of unqualified teachers and reducing the teacher-pupil ratio from 1:50 to 1:25 which recently is reported to be 1:28 (Monkge, 2009).

By 2010 most schools have modern infrastructure, and as there are more schools constructed, students no longer have to walk long distance from home to school and back. The number of unqualified teachers has dropped to about $3 \%$. As a result of the policy of automatic promotion, most pupils remain in school till completion of Primary Education.

There are both public and private schools. By 2010 there were 805 primary schools, $7.5 \%$ are privately owned, with the rest being publicly owned. There are no single gender schools in the country, and the majority of schools are day rather than boarding. There are 32 isolated schools in remote areas, which provide accommodation. Such schools were built for access to education for those who, on account of long distance, could not go to school (Ramahobo, 2010). 
The language of instruction in Grade One is Setswana replaced by English for the remaining duration of their educational career. There are, nevertheless, Batswana who question the policy of using a foreign language, as medium of instruction, at such an early stage in the life of children.

In 2004 the teacher-pupil ratio was 1:25 and by 2010 it was 1:26 According to official statistics, 98\% of the primary school teachers are professionally qualified (Government of Botswana, 2010). The female teachers (75.4\%) outnumber male teachers. It is correct to conclude that in Botswana, all primary school age children have access to Primary Education (Republic of Botswana, 2010).

Ethiopia: In 1980 there were 4,281 government primary schools, and 938 non-government schools (MoE, 1994). By 1990 there were 7,765 government schools and 588 non-government schools. Pupils in government schools do not pay fees, except token amount for various provisions. This is not the case for non-government schools, which depend on fees as their source of income. The medium of instruction is Amharic. It is expected that by 2015, all Ethiopian school age children will have access to Primary Education. It is important to note that in fifteen years, starting from 1996 to 2010, both the number of schools and teachers has grown three times, 273\%, and 286\%, respectively (MoE, 2010).

Lesotho: For a number of decades, Primary Education in Lesotho has been under the domain of the private sector consisting of Catholics, Lesotho Evangelicals (MoE, 2010), African Anglicans, and African Methodists. The schools owned and administered by them are $80 \%$ of all the schools in the country. The remnant of $20 \%$ is under the administration of government and communities. No fees are charged at primary level, which has actually contributed to more children joining school (Instiatuate of Education, 2008). The language of instruction is Sesotho for Grades 1-3. However, Grades 4-7 who are expected to use English as medium of instruction, are taught, contrary to government policy, in Sesotho. In some instances, English which is the official medium of instruction is taught in Sesotho.

Zambia: There are four major agencies involved in the Primary School Education, namely, government, private, grant-aided and community schools (MoE, 2009). About $84.7 \%$ are in the rural areas, community schools emerged in response to shortage of places in the existing schools. This was particularly so for the poor and disadvantaged. By 2009 such schools increased to 2,747 from 55 in $1996 \mathrm{MoE}, 2010$.

After some turbulence on the education landscape, free education was re-introduced from year 2000 up to 2010. Other forms of fees paid for books, uniforms, examinations and stationery were abolished. Moreover, it was strictly forbidden to deny admission to any eligible child who wanted to start Grade 1.

The number of basic education schools rose from 5,324 in 2000 to 8,111 in 2009 (MoF, 2010). Enrolment is more than 100\%, meaning that education for all has been achieved ahead of schedule for the 2015 deadline (Zaken, 2008). Girls getting pregnant while still in schools are no longer expelled. Education is available to pupils with disabilities, orphans and those who are considered vulnerable socially and economically.

Tanzania: There is provision for universal primary school education, and therefore every child has access to Primary Education (URT, 2010). There are government and non-government schools all over the country, with the majority being government schools. No fees other than token fees are charged for Primary Education.

In 2004 there were 7.08 million pupils enrolled, which rose to 8.41 million by 2010 (URT,2010). Both English and Kiswahili are used as medium of instruction. In most public schools, Kiswahili is used as medium of instruction.

Teacher-pupil ration has been fluctuating in the range of 1:33 to 1:54 for the last two decades (URT, 2010). Though teachers are trained, they are not enough to meet the current demand. This lack of housing for teachers is prominent, in the rural areas. However, there is concerted effort to meet the demand by opening new government and private Colleges. Moreover, a good number of universities are offering teacher education for the purposes of producing more teachers needed in the country.

Kenya: Primary Education for Grades 1-8 is available for all children in Kenya in both government and private schools (MoE, 2011). The majority of primary schools are owned and administered by the government through the Ministry of Education. Fees are not charged as education is free. Construction of schools and housing of staff is the responsibility of parents. Teachers are paid by the State.

By 2007 there were 8.3 million pupils in 26,197 schools consisting of 18,397 government and 7800 private schools (MoE, 2011). As a result of free education (2003), there has been an enormous intake of school children. The GER was $114 \%$ for boys and $116.9 \%$ for girls in 2007 . More boys than girls enrolled and the national enrolment rate (NER) was 92\%.(MoE, 2010)

Zimbabwe: All children have access to education from Grades 1-7 (MoE, 2007). There is automatic promotion and as such, there is no repeating Grades which serves as a control of dropouts. There are both government and private schools, the majority of them being government, and the rest are owned and run by private organisations such as NGO's, community and religious organisations.

Mother tongue is the medium of instruction for Grades 1-3, and then English assumes such role in subsequent 
Grades. However, in most schools English is used as a medium of instruction, even in the first three Grades. No fees are charged except for token requirement. The teacher-pupil ratio is 1:40 ( $M o E, 2010)$. The majority of teachers are qualified. By 2006 there were only $3.4 \%$ who were not qualified (MoE, 2007). However, many of the qualified teachers are leaving the country, and some of them are being replaced by untrained teachers.

South Africa: Education is compulsory for all primary school age children, and as such, all children have access to Primary Education (RSA,1996a). The gender parity stands at 0.97 in favour of boys. Gender equality at primary school level is actually excellent. It is planned and predicted that by 2014 , there will be $99 \%$ enrolled in schools, thus meeting the set goal for 2015 (Department of Basic Education, 2011a)

Quality is considered rather low, because of children's poor performance in regional and international standardized tests, though this is a rather questionable criteria for quality. Quality of education cannot exclusively be based on how children perform in such measures. Quality takes into account many factors, such as how they perform in internal and national examinations, number of qualified teachers, availability of teaching and learning materials and the quality of the existing infrastructure. Taking all this into consideration cannot lead to the conclusion that quality is a matter of serious consideration

Nigeria: The highest enrolment was experienced in 2003, when 25 million children enrolled (Federal Ministry of Education, 2009). Urban enrolment is far higher than that of rural areas. There is automatic promotion, thus controlling the number of dropouts considerably. There are 50,000 schools with an enrolment of 20 million, while there are 7.34 million of the school age children are not in school.

There are 86 Colleges of Education as a result of expansion to meet the demand for teachers. However, the expansion has not matched the needed resources, as a result it has an impact on the quality of teachers graduating from such colleges. This inevitably has an impact on the quality of education pupils are receiving. The teacher-pupil ratio stands at 1:37.2. The number of trained teachers is $49.8 \%$ females and $50.8 \%$ males. In terms of gender equality for pupils, there are more boys than girls in the North, whereas in the West there are more girls than boys.

Uganda: Primary schools are both public and private. Education is made available to all and no fees are paid. About $76 \%$ of the schools are government owned and $24 \%$ are private owned (Ministry of Education and Sports, 2010) The GER is over $100 \%$ for years $2009 / 2010$. There is no significant difference between the number of girls and boys' admissions.

The mother tongue is used for instruction at the lower level, whereas English is used at higher level of Primary schools. On the other hand, the situation in most urban areas is different, given that there is population diversity in the languages used. For this reason, English is a medium of instruction.

Most of the teachers are trained and upgraded regularly, which results into excellent pass rate in the national examinations written at the end of Primary Education. This was particularly true with the examinations written at the end of 2009 and 2010, when pass rates of $85 \%$ and $100 \%$, respectively were reported (MoES, 2010).

Rwanda: By 1977,65\% of the children were receiving Primary Education which was considered good among African countries (Rwanda Education, 2011). Primary school cycle of eight years changed to a cycle of six years. Kinyarwanda is used as medium of instruction for Grades 1-3. For the remaining three years, both French and English are taught as subjects. There are schools, however, that prefer to use either French or English as medium of instruction. Fees have been abolished. In 2010 there were 2,299,326 pupils enrolled, with a breakdown of $50.7 \%$ girls and 49.3\% boys (Ministry of Education, 2010). Transition from primary to secondary school stood at $95 \%$, which is considered excellent (MoE, 2010)

Egypt: Primary Education is for six years and for children aged 6-12 years. Such level of education is considered a right to which all children are entitled (The Egyptian Ministry of Education,2010). In 2006/2007 there were 31,600 primary schools, with an enrolment of 11.8 million pupils (The Egyptian Ministry of Education, 2010). The breakdown on the basis of gender was $51.8 \%$ boys and $48.2 \%$ girls (The Egyptian Ministry of Education, 2010). The policy of increasing the enrolment of girls is bearing fruit, as more and more girls have been participating in primary education (Ibid). Both Arabic and English are used as medium of instruction.

Ghana: There are more public urban schools than there are rural schools, whereas private schools are more in rural areas than in urban areas $(\mathrm{MoE}, 2010)$. There are also schools for special needs pupils. Private schools charge fees and their schools are more popular, because of quality education, as reflected in the national examinations results. In public schools, in 2009/2010, 58\% of the teachers were trained, whereas in private schools only a small number of teachers are qualified (11.3\%). The national average of trained teachers is $47.6 \%$. The teacher-student ration is 1:19 in public schools compared to a ratio of 1:24 in private schools. The national primary education completion rate is $87.1 \%$ with a gender breakdown of $89.7 \%$ for boys and $84.3 \%$ for girls. This is excellent!

There are special programmes in operation, which have led to the abolition of direct and indirect fees of any kind, 
including payment for uniforms, books and stationery. In addition lunch are provided to all students. The food is provided with the support of the Dutch Government. Such programmes are known as Free Compulsory Basic Education (FCUBE) and what is referred to as Capitation Grant (MoE, 2010).

FCUBE was introduced in 1995 and was to become a reality by 2005. It aimed at quality of teaching and learning: by increasing learning time; reducing fees and levies; providing in-service training for the improvement of school supervision; prize-giving; increasing level of motivation by means of prize-giving and housing incentives for teachers revising textbooks in keeping with new syllabi; provision of scholarships for girls to enrol and complete basic education.

Capitation Grant meant that for every pupil, the equivalent of US\$ 3.30 is allocated per year, for every child registered in schools. This was to ensure that there would be free education, not only in terms of not paying fees, but also other indirect fees chargeable.

Language policy regarding the medium of instruction has been controversial, mainly based on the use of mother tongue as medium of instruction. For many years mother tongue was used for Grades 1-3, as is the case with most African Union countries.

Namibia: Within ten years following Independence in 1990, enrolment at Primary school level had more than doubled Ministry of Educaation, 2010). As a matter of fact, enrolment in Namibia was more than the average both in developing countries and in Sub-Sahara Africa (MoE, 2010). Currently more than $96 \%$ children are registered at Primary School level. More of these are female than there are males (Ibid, 2011). However, there is concern regarding repetition and retention rates at primary level, with the number of boys exceeding that of girls. More pupils repeat than the average in developing countries.

On the other hand, the Namibian rate is below that of Sub-Sahara Africa. In relative terms, the quality of education is perceived to be unsatisfactory due to a variety of factors: lack of involvement on the part of parents; the mother tongue not being afforded its rightful place in education, and ineffective school management. In terms of urban and rural schools, quality of education is better in the former.

Cameroon: Primary Education is in such demand that there are more and more new students seeking admission in both government and private schools. Based on South West Region of Cameroon, there were 773 public primary schools in 2009, which rose to 1,159 by 2010; while the enrolment was 168,127 public and 80,237 private, making a sum of 248,364 pupils The number of teachers was 3,635 public and 707 private, adding up to 1,240. Three languages are used as medium of instruction, namely English, French and mother tongue. The demand for teachers is being addressed by increasing the number of teachers being recruited to take up a teaching career at college or university.

\section{Primary Schools}

\subsection{Discussion}

Primary school education is intended to satisfy the needs of children whose education ends at this stage, and at the same time meets the need for the successful cohort to pursue secondary education. It is partly from this perspective that the world at large emphasises on access to primary education, not only for some pupils, as the tradition and practice has shown, but that beyond this, there must be primary education for all school-age children qualifying for education. In most of the participating countries, there is universal primary education. In the past three decades,

African countries have made great strides to catch up with developed countries in the shortest time possible, to make primary education universal. Kenya, Tanzania, Uganda, Lesotho, Botswana, South Africa, Ethiopia and others are providing universal primary education to school-age children who are in millions. This, nevertheless, has been achieved without implying that all is well. Such universal education must account not only to access, but also has to take into consideration the gender aspects.

Gender Parity is an important factor, particularly in many African countries where girls and boys are culturally treated differently in favour of boys. In terms of the information provided in each country, gender parity has been handled well, as there is equal number of girls and boys receiving primary education.

\subsection{Secondary School Education}

Secondary school students are a sole resource for the supply to meet the demand at tertiary/university level, otherwise higher learning institutions could as well close down indefinitely Secondary Education is considered necessary as source of manpower: primary schools completers need to pursue Secondary Education and renewed political will and commitment to extension and expansion of secondary education. 
Botswana: Secondary Education began in the 1960's with both public and private secondary schools (Botswana Government, 1993) There were more schools built in the 1980's, which corresponded with large enrolments. There are three types of secondary schools, namely government secondary schools; mission secondary schools partially financed by the government and private secondary schools owned by companies.

With the expansion of Secondary Education, the government resolved to offer free education which boosted the enrolments (Botswana Government,1993). There is equal admission for boys and girls. Both gender equity and equality appear to be good (Matsoga, Lekoko, Tsheko \& Garegae, 2006)

In terms of the distribution of schools, there are 238 government schools and 54 private schools; five of them being boarding schools, three of which are mission and the remaining two belong to the government (Ministry of Education, 2006). The existing language policy is for English to serve as medium of instruction.

The majority of teachers are professionally qualified, and only $3 \%$ are not trained as teachers (Lekoko. 2008). The teacher-student ratio is 1:35. Most children have access to Secondary Education Ministry of Education, 2010). The number of teachers is adequate, with the exception of Mathematics and Sciences, where there is shortage of teachers.

Cameroon: Many more secondary schools have been built in the last three decades, thus reducing the travelling distance between home and school (Cameroon Government, 2011). Based on the information from the South West Region of Cameroon, schools owned and run by government have an enrolment of 92,811 students, and a total number of 3,460 teachers (Ministry of Basic Education, 2011).

Lesotho: In 2010 there were 321 registered secondary schools, 26.2\% were government schools, which was a great contrast with the church owning most of the primary schools in the country (Ministry of Education and Training, 2010). There is access problem for pupils completing Primary Education, and yet there are not enough places for their admission at secondary school level (MoET, 2010.Moreover, many Basotho live on the hills and mountains and schools are generally built in lowlands. This means students have to walk long distances from home to school in the lowlands. There is a new language policy which identifies English, Sesotho and sign language as both official and the medium of instruction.

In both 2009/2010, the number of repeaters was $14 \%$, with more female repeaters than male repeaters, proceeding to higher grades. This presents a contrast to years 2002, 2008 and 2009 when the transition rate of female students was better than that of male students. As part of secondary education programme, the Ministry of Education (2010) places emphasis on: improving access, relevance, quality of education, gender equity and develop HIVIAIDS strategies.

Tanzania: Secondary Education is considered necessary as source of manpower: primary schools completers need to pursue Secondary Education and renewed political will and commitment to extension and expansion of secondary education (URT, 1995). In fact, there is a commitment to have a secondary school for every Ward, as a means of making Secondary School Education universal (URT, 2010).

There are two types of Secondary Education, namely "O" level and "A" level, standing for ordinary and advanced in both government and private secondary schools. In terms of gender parity, boys exceed the number of girls substantially. Every effort is being exerted to improve the enrolment of girls with considerable success (URT, 2008).

English is the medium of instruction, though in a number of cases, teachers have been observed to be teaching in Kiswahili, for a variety of reasons, one being some of the teachers have inadequate mastery of English, and therefore are more at ease with Kiswahili than English.

The teacher-student ratio in 1980 was 1:20 by 2010 it stood at 1:53 (URT, 2010). Urban schools have a low teacher-student ratio, in contrast to rural schools where the teacher-student ratio is rather high. There is shortage of teachers in Mathematics and Sciences, as a result of existing teachers seeking greener pastures in private sectors, parastatal organisations, as well as seeking employment outside the country.

Ethiopia: Since mid-1990's Secondary Education consists of two components, namely general secondary (Grades 9-10) and the preparatory secondary school (Grades 11-12). Increased enrolment at secondary level is in response to two factors: the need for access and quality education and demand for the economy in need of labour force at middle and higher levels, and intake capacity for tertiary levels, reduction of gender parity, geographical disparity particularly for rural students (Ministry of Education, 1985).

Enrolments, numbers of schools and teachers have increased at the rates of $14.1 \%, 13.6 \%$ and 21.4 , respectively (MoE, 2010). The number of qualified teachers is $75.2 \%$. The rate of enrolment based on gender shows that there are more boys than girls at secondary school level, and it will take a while before gender parity in enrolment is attained (MoE, 2010).

Zambia: Secondary School Education is from Grades 10-12. Secondary level falls into three categories namely, government, grant-aided and private, with each category having both day and boarding secondary schools. There are 
672 secondary schools, out of which 531 belong to the government, 141 are administered by private organisations (MoE,2010).

The years 2000 to 2010, saw more access at secondary level than had been the case in the previous years (MoE, 2010). Such rate of increase in enrolment has increased the momentum to construct more schools across the country during the past ten years. Some of such schools are complete, while others are still under construction. For example, between 2000 and 2007, the number of schools rose from 271 to 672 which was an increase of 9.5\% per annum (MoE, 2010). During the same period, enrolment rose from 416,261 to 848,219 , the growth rate being from $13.5 \%$ to $30.2 \%$ (Ibid).

Gender parity index has increased from 0.75 to 100.4 in 2010, meaning there are as many girls as boys who have access to Secondary Education. There are a number of reasons for the increase of girls in secondary schools, and these are as follows: gender re-entry policy; government bursary scheme; initiatives by NGO's, such as Forum for African Women in Education in Zambia; and Campaign for Female Education, supporting girls from vulnerable families, and gender affirmative action allowing positive discrimination in lowering entry points. An example would be 1,863 girls who got pregnant at school in 2009. Out of these, 1,162 were readmitted after giving births. There is a general shortage of teachers as a result of increased enrolments, and the number of teachers being recruited after graduation is insufficient (MoE, 2010).

Kenya The number of secondary schools has increased by $58.1 \%$ from 4,071 in 2003 to 6,432 in 2007, the largest number of 5,127 being public (Ministry of Education, 2011). In 2005 there was an enrolment of 934,140 which increased to $1,507,346$ (Kenya Education Directory, 2011). For the same period, the number of girls rose from 439,992 to 698,876 girls compared to boys, increasing from 494,157 to 808,650 during the same period (MoE, 2011). English is used as the medium of instruction. The gross enrolment rate nationally stood at 37.5 in 2007. On the basis of gender, GER was 39.2 for boys and that of girls stood at 35.8\%. The teacher-pupil ratio in public and private secondary schools: $22: 1$ and 13:1 respectively (Kenya Education Directory, 2011).

Zimbabwe: Secondary Education consists of Ordinary Level (forms I-IV) and Advanced level (forms V-VI), there are both government and private secondary schools divided into day and boarding schools. On joining Form1 and proceeding to Form IV, there is automatic promotion, but have to pass the national examinations to qualify to join Form V.

In 1980 there were 200 secondary schools which increased to 1,548 secondary schools by 1999 (MoE, 2007). This, indeed, was remarkable for a country within two decades of its Independence to make such great leap in the advancement of Secondary Education. English is the medium of instruction, and both Shona and Ndebele are taught as subjects. Most of the teachers are qualified in their teaching subjects, but there is shortage of English, Science and Mathematics teachers (MoE, 2010). As a result of which schools are forced to appoint less qualified teachers to handle such subjects. The shortage of teachers in Mathematics, Science and English is partly attributed to the socioeconomic and political atmosphere, which has led to the departure of teachers to neighbouring and distant countries in search of green pastures.

South Africa: More students are absorbed into secondary schools in South Africa than in most Sub-Saharan African countries (Department of Basic Education, 2011a) Growth in enrolment at secondary school level has a weighted mean of $61 \%$, which is higher than most Sub-Saharan African countries. In 2000 growth in secondary schools was $82 \%$, which by 2007 grew to $91 \%$ The GER is in favour of girls at $88 \%$ compared to $82 \%$ for boys (Ibid). The gender parity is 0.97 by 18 years of age, and more girls than boys complete Grade 12. The gap has been narrowing, for example in 2002, the GPI was 0.92, whereas in 2009 it was 0.98 (DBE, 2010). Participation on the basis of race is as follows: ages 16-18 years in 2009: Coloureds 68\%, Indians $80 \%$, Africans $85 \%$, and Whites $87 \%$. Equity in terms of both boys and girls is excellent; Access has been achieved for both boys and girls (DBE, 2011a).

Poverty presents problems with inequities. Children from poor background are receiving inferior or poor quality of education, and correspondingly their performance is poor, throughout the Education System.

Nigeria: Secondary Education is divided into three years of Junior secondary school and another three years of Senior secondary school. For the past three decades, the number of secondary schools has been increasing every year to cope with the high demand for entry into secondary schools. At the rate of $23.5 \%$ from 1970 , there were 1,379 secondary schools rising to fourfold to 5,876 by 1985 . Yet this increase still leaves many primary school pupils without a place for admission to continue with their education. This is contrary to government policy guaranteeing $100 \%$ entry into Junior Secondary School.

Uganda: Between 1992 and 2010 secondary schools have increased beyond 500 new schools. Moreover, it has been decided as a matter of policy that there will be a a secondary school in every count across Uganda. This is not a commitment on paper, as such schools are being constructed for everyone to see the government in action.

For the purposes of access, in 2006 the government took a very important resolution of making Secondary Schools 
fees free for all those who qualify for admission. English is the medium of instruction. The gender parity index for years 2009 and 2010 was 0.85 and 0.86 , respectively, which is very high compared with other African Union countries.

Egypt: There are two types of Secondary Education, namely general and Technical/vocational. On the basis of recent statistics, general education had an enrolment of 797,711, whereas technical/vocational had 665,489 in both government and private secondary schools in 2008. Both English and Arabic are used as medium of instruction. The number of boys enrolled is greater than that of girls, though the later is on increase through concerted effort. For a variety of reasons, including shortage of teachers, lack of instructional materials, overcrowded classes and limited financial resources, quality education is rather difficult to maintain at secondary school level.

Rwanda: As universal primary education has been attained, this has led to expansion of secondary schools to accommodate the large successful number of pupils in Primary Education. Secondary Education consists of 5 years of Lower and another 3 years of upper secondary.

Starting from 1996, secondary school enrolment has had an increase of $20 \%$ per year so that in 1996, there was an enrolment of 50,000. By 2001 the enrolment trebled, standing at 141,000 students. Such enormous increase was only an introduction of what the future held in store for education Come 2010 there was a gross enrolment of 425,587 students.

The number of schools was 689 and 1,399 for years 2008-2010 respectively, indicating that by 2010 the enrolment doubled. This was nothing short of a superb achievement and record in the history of Secondary Education in Rwanda.

The gender distribution was $50.7 \%$ girls and $49.3 \%$ boys. In more recent statistics, it is recorded that gender parity stands at 50.2\% and51.8\% for the years 2009 and 2010, respectively; clearly demonstrating that gender parity at secondary school level has been achieved.

Namibia: There are both public and private secondary schools with an enrolment of 246,000 in public secondary schools and an enrolment of 164, in private schools. Of the total enrolment, there are $54 \%$ girls and $46 \%$ boys which is very close to gender parity. English is adopted as the language of instruction, which was quite a transition from the use of Afrikaans prior to Independence in 1990.

Ghana: Secondary Education consists of General that is academic and Technical and Vocation Education. In total there are 704 secondary schools with a breakdown of 496 public senior high schools and 208 private senior high schools. Many private secondary schools are single-sex operating as either day or boarding schools. Numerically there are 23 boys' schools only and 33 girls' schools.

So far as teachers are concerned, there are $85 \%$ of trained teachers in government schools and $56 \%$ trained teachers in private schools. In public schools, the teacher-student ratio is 1:21, and the same ratio is maintained in private schools. English serves as a medium of instruction, and has not been contested, as it happened at Primary school levels reported earlier on.

\section{Secondary Schools}

\subsection{Discussion}

Secondary school students are a sole resource for the supply to meet the demand at tertiary/university level, otherwise higher learning institutions could as well close down indefinitely. This brings to memory the Tanzania experience shortly before independence in 1961. President Julius Nyerere made a recommendation to the soon- to-depart British government for the establishment of a university in Tanzania. They did not build a single university for the forty or so years they governed the country. Their response was of ridicule, and asked Mwalimu Nyerere, as to where he was going to get students to admit into such a university?

Their answer was based on the fact that, there weren't students in the country that would have justified the creation of a university. But this did not deter the determination for the establishment of a national university. Therefore the University of Dar es Salaam was established the same year, the British granted independence to the Trust Territory of Tanganyika. But the British were not that far off the mark in their answer, as the University College of Dar es Salaam had no more than seventeen students!

Tracing the history of secondary education in the African countries shows that, before independence these countries had a negligible number of secondary schools staffed by expatriates from the governing nation, Great Britain. Comparatively Uganda had the most because of private secondary schools As a result many students from Kenya and Tanzania pursued secondary school education in Uganda. The author happens to have been one of them. My home, Mbeya, Tanzania, happens to be at the border of Tanzania and Zambia. It used to be a three-day journey, travelling day and night, by bus, train and ship (Lake Victoria). 
In this context, it is amazing that the number of secondary schools in East Africa has skyrocketed to a hundred fold. In Uganda, secondary education has assumed the status of universal secondary education, since a decade ago, meaning that every eligible adolescent is free to join secondary school, free of charge. Congratulations go to those who have been responsible for promoting secondary education, to the extent they have done so..

Moreover, increase of enrolment at secondary is in response to factors such as: the need for access and quality education; demand for the economy in need of labour force at middle and higher levels; intake capacity for tertiary levels, reduction of gender parity and geographical disparity, particularly for rural students.

Additionally, it may be argued that, the expansion of secondary schools was precipitated by political will and commitment to provide such education, as part of the national agenda for national and economic development.

Quantitatively, in terms of access to secondary education, Africa has done an excellent job without question. An examination of gender distribution indicates that, more boys are enrolled at secondary level than girls. Despite the existing disparity, it is one of the goals to see that more girls enrol in secondary education. In the last three decades, there has been visible increase of girls attending secondary school, as indeed also the enrolment of their counterpart has gone up over time.

\subsection{Tertiary/University Education}

University is a tertiary level of education noted for teaching courses of study at an advanced level leading to the awards of certain degrees. In Africa, government have been providing university education as the apex of formal system of education, ordered to educate and train high level manpower required by the economy. Universities are also charged with the role of teaching, undertaking research so as to develop and advance knowledge, store, and disseminate such knowledge.

The university education and training programes have been expected to respond to the demands of national development, emerging social and economic needs, providing solutions to the problems facing the society. Below have been specific objectives of university education in Kenya: (Republic of Kenya 1999 TIQET, 174)

Botswana: The University of Botswana remained the only institution of higher learning for over two decades. During the years, its enrolment increased from 800 students to over 10,000 in the early 1990's. Today, the University is no longer enjoying such status and prestige of being the national university above all else, as there are now five universities. Three of them are government-owned, and the other two are private universities. When the University of Botswana was established, it was, among other things, intended to serve as the source of higher level manpower in as many fields as possible.

The total enrolment at the University of Botswana stood at 11,121 in 2003/04, and by 2008/09 the enrolment rose to a record high of 15,000 students, preparing to serve their nation, with the best and highest qualifications in the land. About $80 \%$ of the work force comprises national academics, and a smaller percentage of expatriates, many of them serving in areas such as, Engineering, Sciences and Mathematical Sciences and English as the medium of instruction, while Setswana is taught as a subject or major for those interested in Languages.

Technical and Vocational Education enrolment rose from 6,208 in 1996 to 13,027 in 2005. There are more males enrolled than there are females. For example, in 2005, 8,500 male students were registered compared to 4,000 female students. There are also more than half a dozen Colleges of Education preparing teachers at primary school level in addition to those pursuing degree programmes at University in preparation for teaching at secondary school level.

Namibia: There are two institutions of higher education, namely the University of Namibia and the Polytechnic of Namibia, both located in the national capital, Windhoek. In each one of these institutions of higher learning, enrolment has been rising on annual basis, given the growing demand for higher education in Namibia. Since and before Independence, there were several Colleges of Education, which as of recent have been incorporated into the Faculty of Education at the University of Namibia. This has been undertaken, as a strategy for improving the quality of teachers at primary and secondary levels in the school system. By improving the quality of teachers, it is assumed that this will have similar corresponding effect on the quality of education at the school system in the country.Cameroon: Technical and Vocational Education was neglected for too long in the socioeconomic transformation of society. It was reserved only for those considered intellectually unable to undertake academically challenging further education in the various disciplines offered at various universities. Parents encouraged their children to pursue education that would enable them to be doctors, lawyers, engineers, accountants and administrators.

However, there is a realisation that Technical and Vocational Education is very important in the creation of jobs and socioeconomic development of society. Many of those who pursued what they considered academic education experience problems finding employment, as their areas are oversubscribed in terms of jobs availability. 
There is a dramatic promotion of Technical and Vocational institutions not only at high school level, but also at tertiary level. At tertiary level, the staffing is very poor, given the shortage of tutors as shown in enrolments of 1,500 for which a single tutor has to mark such a huge number of scripts. Infrastructure is not that good, gender equality in both staffing and enrolment is very low. However, change is on the way, as more women are joining such fields, formerly considered man's domain. Teacher training is on the increase to meet the expansion and increase at primary and secondary school schools.

Throughout the country, there has been increase of Teacher Education programmes as well as Colleges. This has been more noticeable in private organisations who have felt the impact of large number of schools under their leadership. Universities have joined the race of producing teachers on demand in the school system, whether government or private. Courses offered lead to various qualifications, such as degrees, diplomas and certificates.

The first university, Federal University of Yaounde was established in 1953. Since then more universities have been created, without counting those that have been established by other organisations in the country. However, such increase in universities has not satisfied the demand for university education, as more high school graduates aspire to further education at university level.

Sad to comment, that those coming from poor socioeconomic backgrounds are unable to pursue such education, because it is unaffordable. There is an impressive increase of female students at universities across the country. Some of the reasons for less women being enrolled at university are cultural taboos, male chauvinism, religious overtone and lack of financial support.

When the first university was started, there was an enrolment of 500 students. With the existence of eight state universities, there is an enrolment of 15,000 for each university, exclusive of the enrolment in private universities, which were twelve in 2010.

Rwanda: Tertiary Education in Rwanda sums up to 30 institutions, a tremendous achievement, given that there used to be only one university for many years. In terms of enrolment, the number of students has been phenomenal. At the National University of Rwanda (NUR) in its thirty years of existence, dating from 1963 to1996 about 1,900 students completed their studies compared to 11,000 students in half the time, which is fourfold.For the past decade or so, more universities have sprung up both public and private. In 1980, there were more than 1,200 students enrolled at NUR. Come 2001 the enrolment shot up to 17,000 in six public and eight private universities. The growth rate in universities and enrolment is higher in the private sector than in the public sector. In 2010 in the 30 institutions of higher learning, they commanded an enrolment of 60,000 students.

In terms of gender parity, women are outnumbered by men. For example, in 2005 there were 26,796 students out of which 10,543 were female (39\%). In public institutions, there are more male students, whereas in private ones the converse is true, as females are more than male students (55\%).

Egypt: Technical Education is divided into two groups: secondary schools offering programmes in technical, agricultural, commercial and industrial secondary schools offering certification of technicians. This is of three-year duration. The second type takes five years and leads to what is called senior technicians graduating with a diploma. Those who have done well are eligible for admission at university in a related field of study.

There has been a decline in enrolment due to graduates not fitting well in the fulfilment of requirements: those graduating are unable to find work in their area of specialisation and therefore have to search for other jobs in which they are not trained.

There are 17 universities owned by the government and have a student population of 2.5 million. In 1999 there were two private universities which shot up to 14 in 2009, with a student enrolment of 29,852 students. Going back in history of university education, it is significant to note that in 1952, there were three universities with an enrolment of 50,000 students.

This changed following the revolution of 1952, which emphasised on social justice, economic development through expanding education opportunity. In 1971 it was guaranteed that all eligible secondary school students would be given admission at university; that university criteria would be used as yardstick for all; fees were abolished and there was a guarantee for graduates' employment in the civil service.

According to 2006 data, there are 17 government universities, including Al-Azhar University, in Egypt, which have 2.5 million students. In 2009, the number of private universities reached 14, comparing to only 2 universities in 1999, have 59,852 students (The Egyptian Ministry of Education, 2010).

Kenya: University Education is intended for those completing high school; educating and training high level manpower needed for economic development of the nation. Moreover, it is charged with the role of teaching research and service to society, create, preserve and disseminate

The University of Nairobi remained the only university in the country for decades. This has changed, as more 
universities started emerging through the combined efforts of government and private initiatives. By 2010, the number of universities, both public and private, had risen to 53, with a huge enrolment of 118,230 during the 2007/08 academic year. Enrolment in $2008-2010$ rose by $44.7 \%$ from 122,849 to 142,356 in 2008/09.

The development of Technical Education has occupied the attention of the government for the past 30 years. In 2008 the enrolment was 85,200 students; $50.2 \%$ of these were males compared to that of females standing at $49.8 \%$. On the other hand, the enrolment at the youths technical colleges had a larger enrolment of female (57.8\%) students.

Teacher Training Colleges' enrolment increased from 24,228 in 2008 to 26,324 in 2009, which was partly due to the establishment of private sector Colleges of Education.

Zambia: Tertiary Education falls into two categories, namely university and college education. University comprises public institutions under the Ministry of Education, whereas college education consists of private colleges and colleges consisting of Technical-vocation and entrepreneurship training (TEVETA).

College education is for the duration of two-three years, in contrast to university education that lasts between three to four years or a little longer, as maybe the case with the study of Medicine and Engineering. Programmes offered lead to a certificate, diploma and degree.

In 1980 there were the Universities of Zambia and that of Copperbelt. At university level, students pursue degree education to qualify for teaching at secondary school level. Those attending colleges of education teach at basic education level, including senior high school. There are 14 Colleges of Education both public and private. There are also 227 Technical and Vocational Colleges teaching practical and vocational skills.

In the 1990 s only $2.4 \%$ of students had access to university education. Since then, this has changed in view of the fact that between $2000-2010,16$ private and one public universities have been opened as recently as 2008, which adds up to three government universities.

For the purposes of boosting the number of women, $30 \%$ places are reserved for female students. Both poor and bright female students are awarded $100 \%$ bursaries to pursue university education. The remaining category of successful students receive $75 \%$ of the bursary. This leads to improved access rate and quality education.

Ghana: Tertiary Education comprises polytechnics, Colleges of Education and Universities. Colleges of Education sum to 38 and rather interestingly, they are all public, which is rather rare in most African countries. The enrolment of women is $40.8 \%$. For those enrolled in technical education at the college is no more than $10 \%$. There are ten regions in Ghana and each one has a polytechnic to serve the interests of the region in particular, and those of the country at large.

Technical and Vocational Education is considered important in Ghana. It is intended to make provision for middle level workforce, satisfying the industrial and commercial aspects of the country's socioeconomic development. Following educational reform of 1987, the enrolment rose by 50\%. In 2010 the number of Technical Colleges stood at 280, comprising 129 public and 151 private institutions. There is $86.6 \%$ qualified teachers serving such institutions.

University landscape has undergone changes over time. Starting with the University of Ghana established in 1948, close to 20 years later, that is 1971, there was an addition of two universities, namely Kwame Nkrumah University of Science and Technology and the University of Cape Coast. Currently there are six public universities and eighteen private universities. There are more male students (59.4\%) enrolled than female students (40.6\%).Such gender difference has been stable since 2005/06. Prior to this, there was a gradual increase of female student enrolment. The change is attributed to lower admission criteria for female applicants at entry point. English is used as the official medium of instruction.

Uganda: Makerere University dominated university education as the one and only institution of higher education since 1922. That is past history, overtaken by unprecedented mushrooming of over 100 tertiary institutions, offering postsecondary education across the nation. Such institutions may be categorised as public and private at university and college levels.

Universities categorized public are $17.9 \%$ compared to $82.1 \%$ private owned universities, with a total enrolment of 185,341 students a breakdown of 58,991 male students and 44,440 female students. In colleges there is a total enrolment of 62,074 , comprising 33,486 male and 28,588 female students. The gender parity at university is 0.75 , whereas at college is 0.85 . Females' participation at University is at $43 \%$ whereas at college is $46.1 \%$.

South Africa: Over the last twenty years, South Africa has not had any expansion in constructing new universities, though in terms of enrolments, it has experienced tremendous progress. Starting from 2009, 834,000 students were enrolled at university compared to 670,000 who enrolled at the turn of the century.

The $82 \%$ registered students were at the first degree level. At the masters and doctoral level, there were $5 \%$ and 1\%, respectively. At honours level, there were 8\%. During 1990 to 2008 enrolment at university doubled, thus experiencing what has been referred to as massification of higher education. For example, in 1990 the enrolment stood at 56,475 and dramatically increased to 133,420 by 2008. 
South Africa's rate of participation in higher education was $16 \%$ for the period 2004 to 2007, which has remained stable for the past one decade. Such participation rate is significant in so far as university participation rate in SubSaharan Africa is on the average 6\%, but lower than the participation rate of $31 \%$ and $25 \%$ in the Caribbean and Central Asia.

Zimbabwe: Tertiary Education started with the establishment of the University College of Rhodesia and Nyasaland, which during Independence, in 1980, became the University of Zimbabwe Thereafter followed the Open University of Zimbabwe and the National University of Science and Technology.

To date there are nine public and three-church-based universities administered by the Methodists, Seventh-Day Adventists and Roman Catholics. Other tertiary institutions are twelve institutes of Technology Colleges, and 400 private vocational institutions, with an enrolment of 1500 students studying: hospitality, applied arts, business, Information Technology and other skills-based programmes.

The Harare Institute of Technology offers degree-based courses, in addition to certificates and diplomas. Other Colleges are those offering Teacher Education, which is also offered in the Faculties of Education at University level, leading to the award of degrees. They are geared for teaching at secondary and high school levels.

Tanzania: Tertiary Education maybe experiencing what may be referred to, as the fastest growth in the National Systems of Education. For over two decades, the University of Dar es Salaam remained supreme, as the centre of higher education, following the attainment of Independence in 1961. From the 1980's to date, Tanzania prides in having 40 public and private universities, and university colleges spread across the country. In terms of gender enrolments at higher education, in 1990 there were $568(17.07 \%)$ women and 2,759 (72.93\%) men. Five years later, that is 2005, 17,603 (32.2\%) women and 37,331 (67.8) men enrolled. By 2010, 42,016 (35.3\%) women and 76,935 (64.7\%) men were scholarly and vigorously participating in higher education.

Though English is the medium of instruction, there is debate raging whether Kiswahili should not take the position of being the language of instruction. Probably such debate will continue raging for the foreseeable future

Lesotho: Since Independence, the National University of Lesotho was the only institution of higher education in the country. However, as of recent there has risen another University named Limkokwing University of Creative Technology. There are other institutions comprising the Centre of Accounting Studies, Lesotho Agricultural College, the Institute of Development Management, the Lesotho College of Education and Lesotho Institute of Public Administration and Management.

The largest number of students registered at the two Universities and the College of Education. In terms of enrolment at tertiary education, female students outnumber male students substantially. For example, in 2009/2010 at the National University of Lesotho, there were 8,044 females, while there were 3,093 males. For eight out of 13 institutions, there are 8,131 males compared to 15,150 females in pursuit of higher education.

Nigeria: At Independence in 1960, Nigeria had three universities and four polytechnics. In 2013 there were 125 Universities and 183 Polytechnics and Monotechnics, and 86 Colleges of Education responsible for producing teachers for basic education. In 2012 there was an increase of six universities, making one university per zone.

Apart from South Africa, Nigeria has a larger and more diversified tertiary education system in sub-Saharan Africa. The GER in 1998 stood at 6.1\%, which was higher than the GER of 2.3\% for Sub-Saharan Africa then. However, it was lower than that of developing countries of $9.6 \%$ and South Africa of $15.9 \%$ then, as now it is higher in both instances.

Ethiopia: Higher Education started with the establishment of the University College of Addis Ababa in 1900, with an enrolment of 1,000 students. Following this, there were more than half a dozen colleges in various fields which sprang up. These institutions amalgamated to form the well known Haile Selassie University in 1961. This was not the end, as more colleges were founded in the country. While this was the case, it was not adequate to satisfy the demand for secondary school completers seeking admissions in such colleges. Today there are twenty two public and ten private universities, thus making a total of 32 universities. In 2003/04 the government had as many as nine universities under the Ministry of Education, and three other higher education institutions under other Ministries. In addition, there were eight Colleges of Education. The private sector had 64 higher education institutions.

Enrolment in 2005/06 was 173,560 , rising to 420,387 shortly thereafter. In public universities, the number of women was about one quarter of men, whereas in private institution it was about one third of the total enrolment. The GER at University is 5:3\% which is close to GER 6\% average for Sub-Saharan Africa by the year 2000.

Technical and Vocational Education for many years was considered of low status and those who qualified as artisans and technicians were not accorded due recognition and respect, which had impact on those aspiring to specialise in trades.

However, modern education has changed direction, as some of the schools that were academic-based included the curriculum of Technical and Vocational Education. In 1974 there were 5,500 students and 550 teachers in Technical 
and Vocational schools. By 2008/09 enrolment stood at 308,501 students with 9,052 teachers and 458 schools. The percentage of students in terms of gender was $46.2 \%$ females and $53.8 \%$ males, which is an impressive progress made.

\section{Tertiary/University Education}

\subsection{Discussion}

More than fifty years ago, most African countries attained their independence from whatever foreign nation had had the reigns of governance. Prior to independence and during independence years, thousands of African students were sent to Europe, Asia, Australia and America for further studies, in preparation for their participation in the governance of their own respective countries. On completion of their studies, thousands returned to serve the role for which they were sent to further their studies.

Prior to independence and for some, even after independence, they had no university of their own. The rare countries that had such institutions may have had one or two. After independence, most of them made sure that they had at least one university to cater for their national needs. The one or two established then were a monopoly, as they remained the only universities for over two decades, with very little increase in enrolment. Such universities were almost exclusively staffed by expatriates for many years.

Yes, that was the reality of higher education then, and remains part of the history of higher education in Africa. In the past three decades, the landscape of higher education has undergone a total transformation. All steered under the leadership of Africans themselves, in charge of their destiny. Three decades later, there is hardly an African country that has no university of its own. Those that had one or two, which monopolised the scene of higher education for close to two decades, they have been surpassed at an inconceivable speed. Nigeria which had three universities at independence, now has 125; Tanzania 40; Kenya 53; Zambia 19; Rwanda 30; Ethiopia 22; Ghana 24; Egypt 17 and others have universities that far exceed those they have had at any time in their history of higher education. It is not only a question of expansion of geographical space all over the countries, it is also the men and women enrolled in such universities that are immensely amazing and overwhelming numerically. They hold the future of Africa, as a trust in their hands. If there is nothing else Africans can be proud of, they ought to take pride in this spectacular achievement, as it is truly the work of their own hands and minds.

\section{References}

Address by HE Phumzile Mlambo-Ngcuka, Deputy President of the Republic of South Africa at the Conference of Ministers of Education of the African Union, Sandton, Johannesburg, 2007

Ahimbisibwe, P., 2011. PLE: North still struggling to catch up. Sunday Monitor. 23 January, p. 5

African Union, 2010 AUC Deputy Chairperson Mwencha Addresses Ninth High Level Group Meeting on Education For All. Available at: .http://www.appablog.wordpress.com/2010/02/24/auc-deputy-chairperson-mwencha-addresses-ninth-hi [Accessed 15 May 2011].

African Education Ministers, 2010. Call for More Investment in the Sector. Available at: http://www.afriquejet.com/news/african education-mini [Accessed 15 May 2011].

African Education Ministers, 2010. Call for More Investment in the Sector. Available at: http://www.afriquejet.com/news/african education-mini [Accessed 15 May 2011].

African Education Ministers, 2010. Call for More Investment in the Sector. Available at: http://www.afriquejet.com/news/african education-mini [Accessed 15 May 2011].

African Union, 2010 AUC Deputy Chairperson Mwencha Addresses Ninth High Level Group Meeting on Education For All. Available at: .http://www.appablog.wordpress.com/2010/02/24/auc-deputy Available at:chairperson-mwencha-addresses-ninth-hi [Accessed 15 May 2011].

African Union. 2008. Second Session of the Bureau of the Conference of Ministers of Education of the African Union held in Addis Ababa, Ethiopia Meeting on Education For All

African Union 2006 Available at: www.sarpn.org./documents/doo01850/index.php [Accessed 15 May 2011].

African Union, 2010 AUC Deputy Chairperson Mwencha Addresses Ninth High Level Group Meeting on Education For All. Available at: .http://www.appablog.wordpress.com/2010/02/24/auc-deputy- Available at:chairperson-mwencha-addresses-ninth-hi [Accessed 15 May 2011].

African Union 2008 Second Session of the Bureau of the Conference of Ministers of Education of the African Union Held in Addis Ababa, Ethiopia Meeting on Education For All.

Botswana Government 2010. Education Statistics. Gaborone: Government Printers.

Bureau of Statistics, 2011. Registration of Orphans and other Vulnerable Children in Lesotho. Preliminary Report. Maseru: Ministry of Finance and Development Planning

Cohen, C., 1994. Administering Education in Namibia: the colonial period to the present. Creda Press: Cape Town, Republic of South 
Africa.

Conference for African Ministers of Finance and Education: Sustaining Education Gains Amidst the Global Economic Crisis 2009 Held inTunis, Tunisia

GoR 2010. Annual Reports. MINEDUC Kigali

ILO .1982. Basic needs in danger: a basic needs oriented development strategy for TANZANIA. Addis Ababa: International Labour Office

Kibuuka, R., 2011. Mr. President, we want education minister with guts. Daily Monitor. 23 May, p. 12.

Matsoga J, Lekoko, R, Tsheko, N and Garegae K., 2006, A Review of Gender Equity and Equality in Primary and Secondary Education: The Case Study of Botswana - Botswana Educational Research Association, Gaborone: Ministry of Education.

Ministry of Education/Republic of Ghana, 2010. Report on Basic Statistics and Planning Parameters for Basic Education in Ghana 2009/2010.

Ministry of Education/Republic of Ghana, 2010. Report on Basic Statistics and Planning Parameters for Senior High Schools in Ghana 2009/2010.

Ministry of Education, 2010. ETSIP Sub-sector program review as part of the overall Mid-Term Review of the Education Sector and Training Improvement Program (ETSIP). UNESCO Regional Office. Windhoek, Namibia.

Ministry of Education, 2011. National Conference on Education. Collective Delivery on the Education Promise: Improving the Education System for Quality Learning Outcomes, $27^{\text {th }}$ June $-1^{\text {st }}$ July, 2011. Safari Hotel, Windhoek, Namibia.

Ministry of Education 2010. Education Statistics Annual Abstracts 2008-09.Addis Ababa: EMIS 21.

MoE, 1985, Educational Statistics for School-year 1983-84, Addis Ababa:

Ministry of Education, 2010. Report on Basic Statistics and Planning Parametres for Senior High Schools in Ghana 2009/2010.

MoES, 2010a. The education and sports annual performance report for financial year 2008/09. Kampala: MoES.

Ministry of Education, 2010 Report on Basic Statistics on Planning Parametres for Technical and Vocational Education in Ghana 2009/2010.

Ministry of Education, 2010. Report on Basic statistics on Planning Parametres for Tertiary Education in Ghana 2009/2010.

UNESCO, 2006. UNESCO International Bureau of Education.

Ministry of Education, 2011. Basic Report on Spatial Analysis of School Mapping. Ministry of Education 2007.ping Data. Nairobi: Ministry of Education

Ministry of Education, 2006, 10 th Biennial Report. Gaborone: Curriculum Development and Evaluation Department

Ministry of Education, 2007. Education Statistical Booklet 2003-2007. Nairobi: Ministry of Education.

Ministry of Education and Training, 2010. Education Statistics Bulletin. Maseru: Ministry of Education and Training.

Bureau of Statistics, 2011. Registration of Orphans and other Vulnerable Children in Lesotho: Preliminary Report. Maseru: Ministry of Finance and Development Planning.

Ministry of Education, Sport and Culture, 2011.ETSIP: Sub-sector Programme for Review as Part of Overall Mid-Term Review of the Education Sector and Training Improvement Programme (ETSIP). Windhoek: UNESCO.

Ministry of Education 2011 Basic Report on Spatial Analysis of School Mapping Data. Nairobi: Ministry of Education.

Ministry of Education, 2011 Kenya Education Directory - (KED). Nairobi: Publisher \& CEO.

Ministry of Education, 2011. National Conference on Collective Delivery the Educational Promise: Improving the Education System for Quality Learning Outcomes. 27th June 27-July 1, 2011 Safari Hotel, Windhoek, Namibia.

Ministry of Education, 2005. Education and Training Sector: Improvement Programme. Windhoek, Namibia.

MoE, 2008 National Technical and Vocational Education and Training, Addis Ababa: MoE

Ministry of Education 2009. Educational Statistical Bulletin. Lusaka: Ministry of Education.

Ministry of Education 2008. Educational Statistical Bulletin. Lusaka: Ministry of Education.

Ministry of Education and Training and Culture, 1993. Toward Education for All.: A Development Brief for Education, Culture and Training Gamsbrg Macmillan. Windhoek, Namibia

Ministry of Education 2010. Educational Statistical Bulletin. Lusaka: Ministry of Education.

Ministry of Education 1987. Annual Report for the year 1987. Lusaka: Printing Services.

Parsons, Q.N., 1983, Education and Development in Pre- Colonial and Colonial Botswana to 1965. In M. Crowder, Education for Development, Gaborone: Macmillian Botswana Publishing Co

NUR 2010. Report to the Board of Directors.Butare

Parsons, Q.N., 1983, Education and Development in Pre- Colonial and Colonial Botswana to 1965. In M. Crowder, Education for Development, Gaborone: Macmillian Botswana Publishing Co

Ramahobo, S.K. 2011, Primary School Hostel Management Improvement Project, Gaborone: Ministry of Education and Skills Development.

Republic of Botswana, 2010, Education Statistics 2010, Gaborone: Government Printers.

Republic of Botswana, 2005, Education Statistics 2005, Gaborone: Government Printers.

RHEC 2010 Rwanda Higher Education Council 2010 see www.rhec.gov.rw .Kigali

Rwanda Education 2011 Encyclopaedia of the Nation/Africa/Rwanda 2011) Advameg

Sebatane, E. M., Ambrose, D. P., Molise, M. K., Mothibeli, A., Motlomelo, S. T., Nenty, H.T., Nthunya, E. M., \& Ntoi, V.M., 2000. Review of Education Sector Analysis in Lesotho: 1978-1999. Paris: UNESCO.

The Egyptian Ministry of Education, 2010, Basic Education Drop out by Sex in Governorates: Individuals from 6 to less than 18 years 
old, Final Results of Population, Housing \& Establishment 20006 Census

The Egyptian Ministry of Education, 2010, Development of Classes No. In Technical secondary Education (2000/01 -08/2009).

The Egyptian Ministry of Education, 2010, General Preparatory Education (2000/01-08/2009).

The Egyptian Ministry of Education, 2010, General Secondary Education (2001- 2009).

The Egyptian Ministry of Education, 2010, Public Universities in Egypt.

The Egyptian Ministry of Education, 2010, Students' Enrolment in General Primary Education (2001 -2009).

The Egyptian Ministry of Education, 2010, Teachers \& Students in General Preparatory Education by Sex \& Gov. (2008/2009).

The Egyptian Ministry of Education, 2010, The Intermediate Technical Institutions (2002/03-2008/09).

The Egyptian Ministry of Education, Teacher \& Students in Pre-Primary Education by Sex and Governorate (2008/2009).

The Egyptian Newspaper Al-Ahram, 12 May 2011.

TCU, 2009. Universities and University Colleges: Facts and Figures. Dar es Salaam: TCU Publications

TCU, 2011b. The Universities and University Colleges of Tanzania. Dar es Salaam: TCU Publications

Track Initiative 2009 African Ministers Appeal to Donor Countries to Keep Poor Students in School During the Economic Crisis and Beyond. Available at: http://www.campaign for education.org/en/news/education-news/267changes-to-education-for-a-fas [Accessed 15 May 2011].

Uganda Bureau of Statistics, 2010. Uganda national household survey 2009/2010: Socio-economic module, Abridged Report. Entebbe: UBOS.

Ministry of Education, 2011. Basic Report on Spatial Analysis of School Mapping. Ministry of Education 2007.ping Data. Nairobi: Ministry of Education

University of Botswana, 1980. Report of the National Commission on Education. Gaborone: Government Printers.

URT, 1985. Basic Education Statistics in Tanzania (BEST), 1980 - 1984: National Data. Dar es Salaam: Ministry of Education

URT, 1995. Education and Training Policy. Dar es Salaam: Ministry of Education and Culture.

URT .2004a. Basic Education Statistics in Tanzania (BEST), 1995 - 2004: National Data. Dar es Salaam: Ministry of Education and Culture

URT .2008. Basic Education Statistics in Tanzania (BEST), 2004 - 2008: National Data. Dar es Salaam

URT, 2010. Basic Education Statistics in Tanzania (BEST) 2006-2010: Revised National Data. Dar es Salaam: Ministry of EducationPress 'A'

URT, 1985. Basic Education Statistics in Tanzania (BEST), 1980 - 1984: National Data. Dar es Salaam: Ministry of Education

URT, 1995. Education and Training Policy. Dar es Salaam: Ministry of Education and Culture.

URT .2004a. Basic Education Statistics in Tanzania (BEST), 1995 - 2004: National Data. Dar es Salaam: Ministry of Education and Culture

URT .2008. Basic Education Statistics in Tanzania (BEST), 2004 - 2008: National Data. Dar es SalaamxURT, 2010. Basic Education Statistics in Tanzania (BEST) 2006-2010: Revised National Data. Dar es Salaam: Ministry of Education-Press 'A'

UNESCO, 2006. UNESCO International Bureau of Education.

Zaken, B 2008 Primary Education in Zambia. IOB Impact Evaluation The Hague: OBT. 